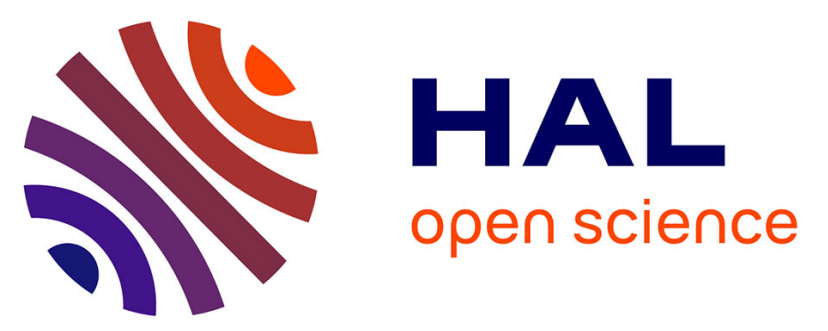

\title{
REFRACTION OF DIRECTED SHOCK ELECTRONS AT PLANAR SOLID SURFACES
}

H. Rothard, K. Kroneberger, M. Burkhard, C. Biedermann, J. Kemmler, O. Heil, K. Groeneveld

\section{- To cite this version:}

H. Rothard, K. Kroneberger, M. Burkhard, C. Biedermann, J. Kemmler, et al.. REFRACTION OF DIRECTED SHOCK ELECTRONS AT PLANAR SOLID SURFACES. Journal de Physique Colloques, 1989, 50 (C2), pp.C2-105-C2-110. 10.1051/jphyscol:1989219 . jpa-00229417

\section{HAL Id: jpa-00229417 https://hal.science/jpa-00229417}

Submitted on 1 Jan 1989

HAL is a multi-disciplinary open access archive for the deposit and dissemination of scientific research documents, whether they are published or not. The documents may come from teaching and research institutions in France or abroad, or from public or private research centers.
L'archive ouverte pluridisciplinaire HAL, est destinée au dépôt et à la diffusion de documents scientifiques de niveau recherche, publiés ou non, émanant des établissements d'enseignement et de recherche français ou étrangers, des laboratoires publics ou privés. 
JOURNAL DE PHYSIQUE

Colloque $C 2$, supplément au $\mathrm{n}^{\circ} 2$, Tome 50, février 1989

C2-105

REFRACTION OF DIRECTED SHOCK ELECTRONS AT PLANAR SOLID SURFACES

\author{
H. ROTHARD, K. KRONEBERGER, M. BURKHARD(1), C. BIEDERMANN( ${ }^{2}$ ), \\ J. KEMMLER, O. HEIL and K.O. GROENEVELD \\ Institut für Kernphysik der Johann-Wolfgang-Goethe-Universität August- \\ Euler-Strasse 6, D-6000 Frankfurt/Main 90, F.R.G.
}

\title{
Resunte
}

Shock electronsk sont des électrons secondaires de faible énergie ( $E_{0}<20 \mathrm{eV}$ ) qui sont produits par des ondes de choc dans le plasma d'électrons (>waker) d'un solide bomdardé avec des ions lourds de grande vitesse ( $V_{P}>V_{\text {Bohx }}$ ). Ils ont été observés en mesurant la distribution en angle et en énergie des électrons secondaires émergeant d'une cible mince. Ces électrons, qui traversent le volume du solide perpendiculairement quant au cône de l'onde de choc, peuvent être utilisés pour étudier la diffraction des électrons lents a la surface du solide.

\section{ABSTRACT}

Shock electrons are ejected in a direction perpendicular to the shock front of the wake cone, the ion induced collective electron density fluctuation in the electron plasma of the solid. They have been observed by measuxing doubly differential secondary electron distributions from thin solid foils in forward direction. Shock electrons represent a unique internal source of directed secondary electrons and thus offer the possibility to study the refraction of electrons at a solid surface. Nearly planar, smooth solid foil surfaces are obtained by sputter-cleaning in ultrahigh vacuum. The smoothing can be observed by scanning electron microscopy.

PACS: $79.20 \mathrm{rf}, 79.20$ ne

\section{INTRODUCTION}

The interaction of swift ions $\left(V_{P} \geq V_{B}\right)$ with condensed matter results in the production of internal secondary electrons by the primary ions, recoil ions, secondary electrons and, possibly, photons [1]. The internal flux of the secondary electrons (i.e. their energy- and angular distribution) depends on both the prinary processes and the transport of electrons through the solid [2]. The distribution of secondary electrons outside of the solid is strongly influenced by the transmission of secondary electrons through the surface potential barrier. Secondary electron creation is important e.g. for" radiation physics, -chemistry and -biology [1]; fusion research for controlled thermonuclear power production (plasma-wallinteractions) [2]; ion induced desorption of molecules from solids (Plasma Desorption Mass Spectrometry, PDMS) [3] and nuclear track formation [2]. Therefore, it is desirable to know both the internal and the external energy- and angular distribution of secondary electrons.

The measurement of energy- and angular distributions of secondary electrons enitted from a solid surface yields valuable information about production, transport and transmission of secondary electrons. In particular, the measurement of secondary electron distributions from thin foils in forward direction yields more detailed information than measuring secondary electrons emission from thick saiples in backward direction. This is due

(1) Now at Kraftwerk Union (KWU), Offenbach, Germany

(2) Present address: University of Tennessee, Knoxville, TN 37996 and Oak Ridge National Laboratory, Oak Ridge, TN 37831 , USA 
to the following reasons: 1. 8-electrons from binary collisions are mostly ejected in forward direction. 2. Convoy-lectrons [2] are observed strongly peaked in forward direction. Also, 3. the directed shock electrons are ejected in forward direction and offer an elegant possibility to study the refraction and transmission of low energy electrons created in the bulk at the surface potential barrier.

\section{"WAKE" AND SHOCK BLECTROAS}

"It is conceivable that the rich spatial shock-wave structure of electron density fluctuations in the wake of an ion may have interesting manifestations in experinent and important consequences for the behaviour of matter under high-intensity ion-beam bombardment." (Ritchie, Echenique, Brandt and Basbas 1979 [4])

The collective response of the electron plasma of a solid to a penetrating swift heavy ion manifests as an electron density fluctuation with axial symmetry [4]. This dynamic polarization "wake" shows the characteristic behaviour of Mach shock waves propagating in cones through the solid [5]. It has been shown that this leads to the directed emission of shock electrons in a direction perpendicular to the shock wave front $[5,6,7]$.

Shock electrons can be detected as peak structures in the angular distributions of secondary electrons at energies $E_{a} \approx 5 \mathrm{eV}$, superimposed on the "true" secondary electron back ground [7]. Experimental details are described in $[7,8]$. The calculated preferential emission angle $\theta_{\text {emmeo }}$ of shock electrons depends mainly on the plasma frequency $\boldsymbol{\omega}_{P}$ of the target and the projectile velocity $V_{P}$ and is given by the Mach relation:

$$
\theta^{\text {theom }}=\operatorname{arc} \cos \mathrm{V}_{\mathrm{a}} / \mathrm{ve}
$$

( $v_{a}=f\left(\omega_{p}\right)$ is the velocity of the shock wave). It has been observed that the emission of shock electrons as well as the emission of electrons from the single-electron deexcitation of heavy-ion-induced plasmons, a collective effect closely related to wake phenomena [8], depend on surface properties such as the coverage with impurities and the roughness of the surface [7]. In this paper, we will discuss the following topics: 1. Nearly planar solid surfaces obtained by sputtering of thin solid foil surfaces with noble gas ions, 2. Refraction of low energy electrons at a planar surface potential barrier, 3. Application of this model to the emission of shock electrons: The experimentally observable mean shock electron

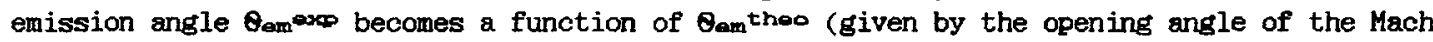
cone of the wake) and the height of the surface potential barrier $U$.

\section{REFRACTION OF GLECTRONS AT A PLANAR SURFACB BARRTER}

Secondary electron emission depends strongly on both the coverage of solid surfaces with impurities and the roughness of the surface $[8,10]$. To study secondary electron emission from clean solid foil surfaces, they have to be sputter-cleaned with noble ges ions $\left(\mathrm{Kr}^{+}, 2 \mathrm{MeV}\right)$ in ultra high vacuum $\left(\mathrm{p} \leq 10^{-7} \mathrm{~Pa}\right)$. The sputtering process at the entrance surface of the beam (backward sputtering) and at the exit surface in forward direction (transmission sputtering). results in both a cleaning and a smoothing of the surface by preferential sputtering. The composition of the surface can be supervised by Ion Induced Auger Electron Spectroscopy (IAES), Secondary Electron Spectroscopy (SES), Rutherford Forward/ Backward Scattering Spectroscopy (RFS/RBS) and Elastic Recoil Detection (ERD). In addition, it is important to analyze the residual gas with a quadropole mass spectrometer, especially to verify that a vacuum almost free of hydrocarbons has been obtained [11]. ARS and SES are very sensitive methods to control the surface, whereas RFS, RBS and ERD can be used to control the composition of the whole target volume. Furthermore, RFS and ERD allow the detection of light elements such as $H$, which can play an important role for secondary electron emission [10]. Before cleaning, the foil surfaces are covered mainly with $\mathrm{C}, \mathrm{O}$ and $\mathrm{H}$, mostly as hydrocarbons and water $[10,12]$.

The reduction of the surface roughness can be observed in two ways. 1. Visually (in situ), because the targets become mirror-like with a highly enhanced reflectivity at the beam spot, and 2. by Scanning Electron Microscopy (SEM) of the target surface. In the pre- 


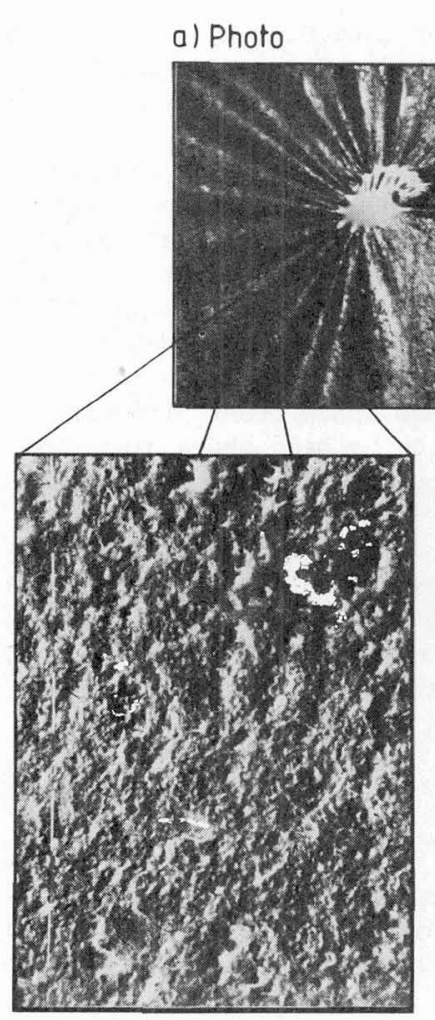

b)SEM uncleaned surface
Fig.1: Exit surface of a Au foil (1000 A) bombarded with noble gas ians ( $\left.\mathrm{Kr}^{*}, 2 \mathrm{MeV}\right)$. a. Photograph, b. SEM micrograph of the uncleaned surface region, c. SEM micrograph of a sputtercleaned beam spot.

sent case, the SEM micrographs have been taken outside the scattering chanber. Therefore, we chose an inert gold foil to demonstrate the smoothing of the surface under the assumption that the structure does not change strongly during the transport from the experiment to the electron microscope.

Fig. 1a shows a photograph of the exit surface of a 1000 \& gold foil. Two bright beam spots are clearly visible. They have a highly enhanced reflectivity compared to the environment. Fig. Ib presents a SEM micrograph of the uncleaned surface region with pronounced struc tures in the $\mu \mathrm{m}$ range. In contrast, Fig.1c shows a SEM micrograph of a sputtercleaned beam spot. No structures can be detected (resolution better than $0.05 \mu \mathrm{m}$ ), except for micro holes (black, no secondary electron emission). Such micro holes appear when the target has been bombarded with heavy ions for an extended period of time. Eventually, the ion bombardment results in the destruction of the thin foil.

The clean, smooth surface can be described in a good approximation by a planar electrostatic surface potential. When a secondary electron $\left(e^{-}\right)$produced inside the solid approaches the surface with sufficient kinetic energy to overcome the nearly planar surface potential barrier $\mathrm{U}(\mathrm{x})$, it is subject to a diffraction phenomenon (Fig.2). The components of the electron velocity vector parallel to the surface remain unchanged $\left(v_{1} "=v_{0} "\right)$, whereas the component perpendicular to the surface is reduced according to the height of the surface barrier $U\left(v_{0} \perp<v_{1} \perp\right)$. The kinetic energy of the electron is reduced $\left(E_{e}=E_{1}-U\right)$. 


\section{RERRACTION OF SHOCK EILETHONS}

An internal source of directed electrons is needed to study directly the refraction of low energy secondary electrons produced inside the solid at the interface between the solid and the vacuum. Secondary electrons can be produced by a multitude of superimposed production mechanisms. Only two kinds of secondary electrons are ejected and strongly peaked in one direction:

1. Convoy electrons are emitted in the direction of the beam, but they are not the appropriate tool to study surface refraction phenomena: It has been shown that their velocity is equal to the projectile velocity [12]. They are not accelerated or decelerated by the surface potential barrier because of their strong correlation to the projectile $[2,10$, 12]. In contrast, the yield of low energy convoy electrons depends on the height of the surface potential barrier [10]. This resembles the reflection of a wave packet at a potential step.

2. Shock electrons move in a direction perpendicular to the wake shock front. The wake is a long-range and nonlocalized phenomenon. Thus, the correlation between shock electrons and the projectile is not so strong as in the case of convoy electrons. They represent a unique internal source of directed electrons.

When shock electrons are transmitted through the surface, they are refracted as discussed in the previous section (Fig.2). The experimentally expected emission angle Bemess becomes a function of the height of the surface barrier $U$, the mean energy of the shock electrons outside the solid $E_{e}$, the "theoretical" mean emission angle Gemeo (given by the opening angle of the wake cone $\theta_{e m}$ theo $=f\left(\omega_{e}, v_{p}\right)$ ) and the target tilt angle $\delta$ (see Fig.2):

$$
\begin{aligned}
\theta_{\text {em }} & =f\left(\theta_{e m} \text { theo }, U, E_{\Theta}, \delta\right) \\
& =\delta+\operatorname{arc} \sin \left[( 1 + U / E _ { \Theta } ) ^ { 1 / 2 } \operatorname { s i n } \left(\theta_{e m}\right.\right. \text { theo-8)] }
\end{aligned}
$$

It should even be possible to detect shock electrons from the backside of a solid tanget, if the target tilt angle is large, the plasme frequency is low and the projectile velacity is high (

$$
\theta_{e m}=180^{\circ}-\delta-\operatorname{arc} \sin \left[\left(1+U / E_{\theta}\right)^{1 / 2} \sin \left(180^{\circ}-\delta-\theta_{e m}{ }^{\text {theo }}\right)\right]
$$

Fig. 3 shows the observed mean shock electron emission angle $\theta_{\text {em }}$ for carbon targets ( $h u_{\mathrm{f}} \approx 21 \mathrm{eV}$ ) as a function of the projectile velocity ve (open circles, from [7]). The (measured!) mean energy of shock electrons outside the solid is Eo $\approx 5 \mathrm{eV}\left(\delta=45^{\circ}\right)$. The dashed line shows $\theta_{e m}$ theo, neglecting the surface potential (U $=0$, from [5]). The dotted line shows $\theta_{\mathrm{em}} \mathrm{ex}$ if $\mathrm{U}$ is chosen to be $U=\Phi+E_{F}(\approx 20 \mathrm{eV}$ for carbon). In theoretical considerations concerning secondary electron emission the total electrostatic surface potential $U$ is often chosen as effective surface potential [1]. This choice fails in describing the experimental data, because shock electrons originate from the electron plasma of the solid with initial energies close to the Fermi energy, EF. The appropriate choice of an effective surface potential in this case should be $U=\Phi$, where $\Phi$ is the electron work function. The same argument is valid for electrons resulting from the decay of plasmons, which can be observed at energies $E<M_{P}-\Phi[9,13]$. Indeed, the expected mean emission angle of shock electrons $\theta_{\mathrm{am}}$ asp (solid line, with $\theta_{\mathrm{em}}$ thao taken from [5] and $U=\Phi=5 \mathrm{eV}$ )

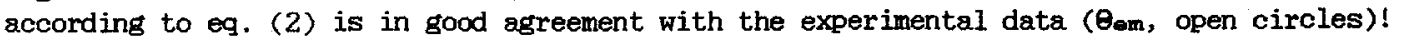

\section{COMCLUSION AND OHILOR}

The heavy-ion-wake-induced shock electrons can be used to study the refraction of low energy secondary electrons, which have been produced in the bulk of a solid, at the surface. There are interesting questions, as e.g. "Is the wake reflected at the surface?", "How many shock electrons can overcome the surface potential barrier and how many shock electrons are retained by the surface potential barrier?". They may possibly be addressed by measuring the mean enission angle bem and energy Ee of shock electrons as a function of the target tilt angle $\delta$. 

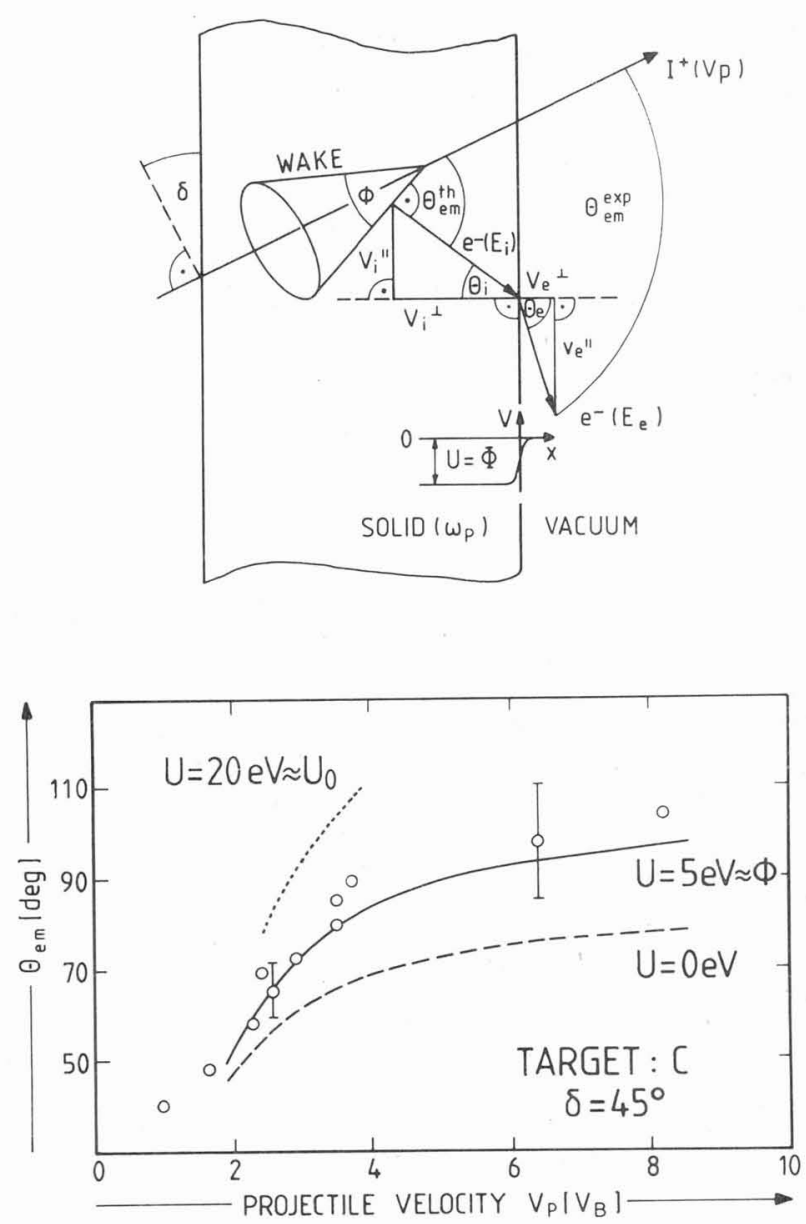

Fig.2: Refraction of shock electrons at a planar solid surface (see text).
Fig.3: The abserved preferential emission angle lem of shock electrons (open circle) as a function of the projectile velocity ve. Dashed line: Cem theo neglecting electron refraction at the surface $(U=0)$, Dotted line: Bamexp $\left(U=20 \mathrm{eV}=E_{F}+\Phi\right)$, Solid Iine: Expected preferential emission angle $\mathrm{Bam}^{\mathrm{exp}}$ $(U=\Phi=5 \mathrm{eV})$.

Another interesting experiment may be the measurement of the angular distribution of heavy ion induced photons emitted from solids. Possibly, photons may be produced by the fast ion-induced electron density fluctuations. These photons are expected to be enitted coherently in a preferential direction depending on the opening angle of the wake cone [14]. Their energy is estimated to be in the range $10 \mathrm{eV} \leq \mathrm{hr} \leq 1000 \mathrm{eV}$. Also, experiments on the temperature dependence of secondary electron emission and, in particular, shock electron emission, may give important information about thermal and electrical transport properties, not only in metals, but even in superconductors [11].

This work has been supported by the German Bundesminister für Forschung und Technologie (BMFT) / Bonn, under contract number O6 OF 173/2 Ti476, and DFG / Bonn. One of us (H.R.) acknowledges a grant from the Willkom Stiftung, Frankfurt am Main. 


\section{PEETEREICES}

[1] P.Sigmund S.Tougaard

Electron Emission from Solids during Ion Bombardment

Springer Series in Chemical Physics 17 (1981) 2

[2] K.-O.Groeneveld

Nuclear Track Formation related Electron Production and

Transport from Ion Penetration through Solids

Journal of Nuclear Tracks (1988) in print

[3] K. Wien, O.Becker, W.Guthier, S.Della-Negra, Y.LeBeyec, B.Monart, K.Standing,

The Charge State Dependence of Desorption

A way to study the Energy Transfer to the Surface

Int. Journal of Mass Spectr. and Ion Processes 78 (1987) 273

[4] R.H.Ritchie, P.M.Echenique, W.Brandt, G.Basbas

IFEE Trans. Nuc1. Sci. 26 (1979) 1001

P.M.Echenique, R.H.Ritchie, W.Brandt

Spatial Excitation Patterns Induced by Swift Ions in Condensed Matter

[5] W.Schäfer., H.Stöcker, B.Müller, W.Greiner

Mach Cones induced by Fast Heavy Ions in Electron Plasma

2. Phys. A288 (1978) 349

Mach Shock Electron Distributions from Solids

Z. Phys. B36 (1980) 319

[6] D.K.Brice, P.Sigmund

Secondary Electron Spectra from Dielectric Theory

Mat. Fys. Medd. Dan. Vid. Selsk. 40 (1980) No.8

[7] M.Burkhard, H.Rothard, C.Biedermann, J.Kemmler, K.Kroneberger, P.Koschar, O.Heil, K. -0.Groeneveld

Heavy-Ion-Induced Shock Electrons from Sputter-cleaned Solid Surfaces Phys. Rev. Lett. 58 (1987) 1773

H.Rothard, M.Burkhard, C. Biedermann, O.Heil, D.Hofmann, J.Kemmler, P.Koschar, Kiectroberger, K. - 0 . Groenneveld

Electron Emission from Collective Excitation of Solids by Heavy Ion Impact

H.Rothard, M.Burkhard, J.Kemmler, C. Biedermann, K.Kroneberger, P.Koschar, 0.Heil, K. -O. Groeneveld

Shock Electrons from Ion-Solid Penetration

$J$. Physique (Paris) 48 (1987) C9-211

[8] M.Burkhard, H.Rothard, J.Kemmler, K.Kroneberter, K. -0.Groeneveld Surface Characterisation of thin Solid Foil Targets by Ion Impact J. Phys. D21 (1988) 472

[9] M.E.Burkhard, H.Rothard, K. -0.E.Groeneveld Single-Electron Deexcitation of Volume Plasmons induced by Heavy Ions in Thin Solid Foils physica status solidi (b) 147 (1988) 589

[10] H.Rothard, M.Burkhard, C.Biedermann, J.Kemmler, P.Koschar, O.Heil, K.Kroneberger, D. Hofmann, K. -0 Groeneveld Influence of Solid Surfaces on Low Energy Convoy Electron Emission $\mathrm{J}$. Phys. $\mathrm{C}(1988)$ in print

M.Burkhard, H.Rothard, C.Biedermann, J.Kemmler P. Koschar, K. -O.Groeneveld Strong Convoy Electron Yield Dependence on Surface Properties Nucl. Instrum. Meth. B24/25 (1987) 143

[11] H.Rothard, P.Lorenzen, N.Keller, O.Heil, D.Hofmann, J.Kemler, K.Kroneberger, Temperature Dependent Secondary Electron Yield from Ion Bombardment of Gold and Copper Oxide Superconductors Phys. Rev. B38 (1988) October 1

[12] S.Suarez, A.R.Goni, H.Meckbach, P.R.Focke

Do Solid Surface Potential Barriers retard Convoy Peak Electrons?

Z. Phys. D 6 (1987) 55

[13] D.Hasselkamp, S.Hippler, A.Scharmann Ion-induced Secondary Electron Spectra from Clean Metal Surfaces Nucl. Instrum. Meth. B18 (1987) 561

[14] Dieter Hofmann, Institut fuer Kernphysik, Frankfurt am Main, Germany, private communication (1987) 